Scientists uncover protein that regulates the body's immune response to cytomegalovirus infection

Study also offers explanation for susceptibility of cytomegalovirus infection in patients with Crohn's disease.

Cytomegalovirus (CMV) is a common pathogen that causes lifelong infections and in newborns can lead to serious neurological damage. Now, a team of researchers from Johns Hopkins Children's Center (MD, USA) have reported the identification of a protein, known as NOD2, as playing a significant role in regulating the body's response to human CMV infection. NOD2, found in various types of immune cells, is known as an important innate immune sensor of bacterial pathogens, but this is the first evidence of its role in sensing DNA viruses.

Ravit Boger, Associate Professor from the Division of Pediatric Infectious Diseases and senior author of the study, commented, "Our results shed new light on the interaction between CMV and the immune system, which we hope will open up a field of opportunities for treatment and prevention." It is now hoped that NOD2 may provide opportunities

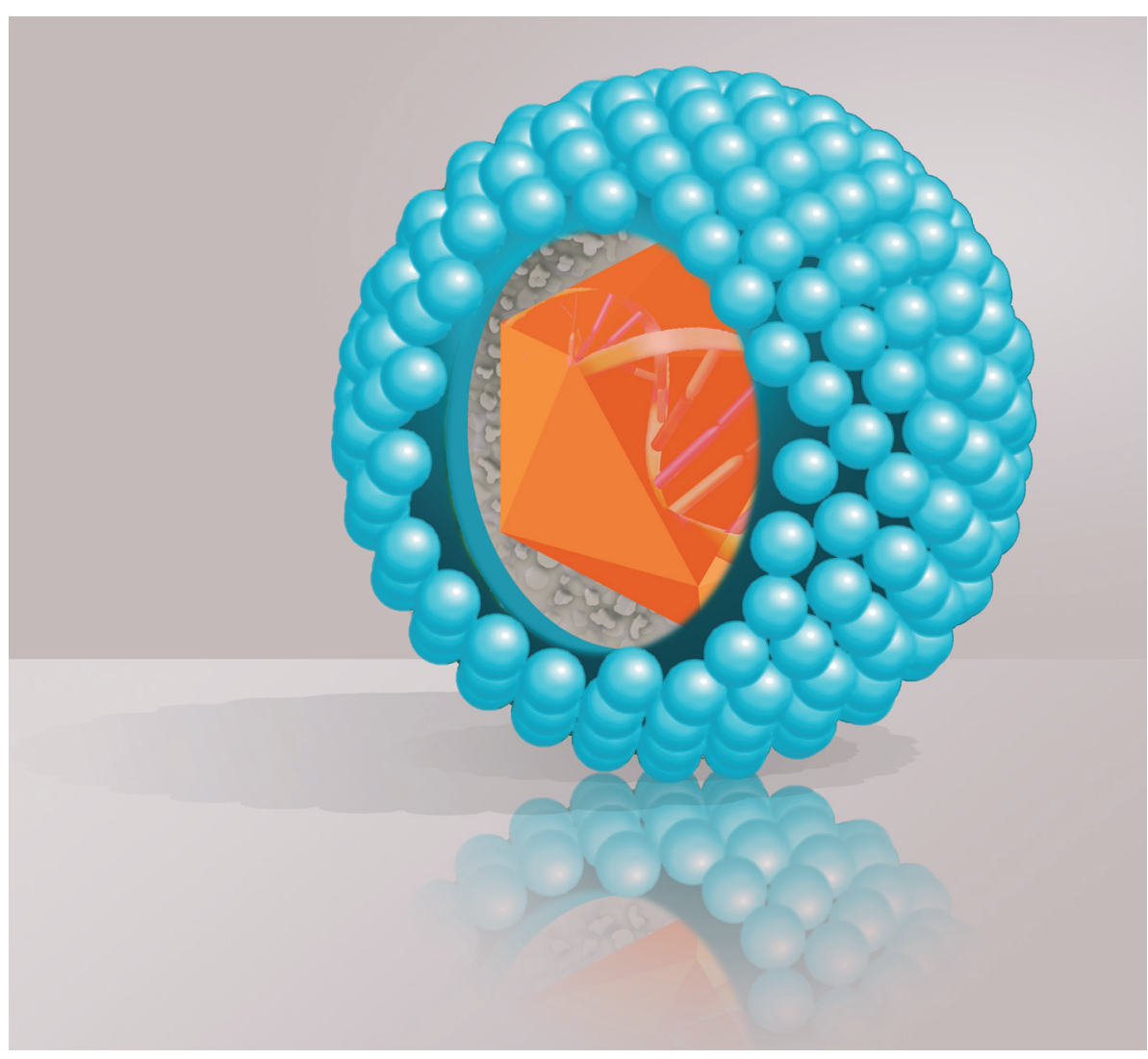

\section{in the news...}

- Lead story: Scientists uncover protein that regulates the body's immune response to cytomegalovirus infection

- WHO South-East Asia region has been certified as polio free pg 584

- Effectiveness of Tamiflu ${ }^{\circledast}$ during swine flu pandemic assessed pg 584

- Light-activated antimicrobial surface is also effective in the dark, study suggests pg 585

- Priority Paper Alerts pg 586 


\section{BULLETIN BOARD}

to modify the body's immune response to CMV and possibly lead to the development of a vaccine.

The findings also provide explanation for the fact that severe CMV infections can occur in patients with Crohn's disease, as the NOD2 protein is regulated by a gene implicated in Crohn's. Boger adds that the results challenge the belief that people with Crohn's are susceptible to CMV infection as a result of the immnosuppresive drugs they receive to control inflammation, a perception that inspired this latest research after a patient with Crohn's also presented with CMV, the presence of which was revealed following a gut biopsy.

In order to test their theory, the scientists tested the effect of CMV and herpes simplex type 1 and 2 viruses on connective cells from human skin, demonstrating that the NOD2 receptors of CMV-infected cells showed robust activation in comparison to uninfected cells. Importantly, the same NOD2 receptors showed no activation in herpes-infected cells. Following this, the group compared human cells with intact NOD2 receptors and those with defective or missing receptors. They found that those cells with intact $\mathrm{NO} 2$ receptors secreted higher levels of interferon, a natural antiviral protein, compared with the missing or defective cells. As a result, these 'defective' cells had up to $70 \%$ more virus than 'intact' cells. Genetic analysis subsequently revealed that a single misplaced amino acid renders the NOD2 receptor incapable of sensing CMV.
"Taken together, our results suggest that activation of the NOD2 receptor induces the immune system to fight off CMV," concluded Boger. "They also suggest that a defective NOD2 could be the culprit behind severe CMV infections in some patients with Crohn's disease." In the future, the group plans to study the course of CMV infection in patients with Crohn's who carry the NOD2 mutation.

\section{- Written by James Potticary}

Sources: Kapoor A, Forman M, Arav-Boger R. Activation of nucleotide oligomerization domain 2 (NOD2) by human cytomegalovirus initiates innate immune responses and restricts virus replication. PLOS ONE 9(3), e92704 (2014); Johns Hopkins Children's Center press release: Researchers identify protein that helps control CMV: http://hopkinschildrens.org/Researchers-Identify-Proteinthat-Helps-Control-Common-Viral-Infection.aspx

\section{WHO South-East Asia region has been certified as polio free}

A region that is home to $25 \%$ of the world's population is now thought to be polio free, which brings the total world's population that now lives in certified polio-free regions up to $80 \%$. Consequently, the goal of eradicating the disease is looking more achievable.

Polio is a crippling and sometimes fatal infectious disease for which there is no cure; only safe and effective vaccines are available. Thus, the strategy to eradicate polio is to prevent infection by immunizing every child until transmission stops. This depends on healthcare workers being able to reach the most vulnerable communities.

Poonam Khetrapal Singh, Regional Director for the WHO South-East Asia Region, explained: "This is a momentous victory for the millions of health workers who have worked with governments, nongovernmental organizations, civil society and international partners to eradicate polio from the region. It is a sign of what we can bequeath our children when we work together."

However, while celebrating the historic achievement, Khetrapal Singh also expressed a word of caution: "Until polio is globally eradicated, all countries are at risk and the region's polio-free status remains fragile. High immunization coverage can prevent an imported virus from finding an underimmunized, susceptible population. A sensitive surveillance system, able to quickly detect and identify any importation and guide a programmatic response, is critical."

- Written by Natasha Leeson

Source: WHO press release: www.searo.who.int/ mediacentre/releases/2014/pr1569/en/

\section{Effectiveness of Tamiflu during swine flu pandemic assessed}

\section{Study suggests that Tamiflu ${ }^{\oplus}$ reduces the risk of death by 25\% in adults hospitalized with H1N1 pandemic influenza.}

During the 2009-2010 influenza A H1N1 pandemic, neuraminidase inhibitors (NAIs), such as Tamiflu ${ }^{\circledR}$, were commonly used. However, it was unknown how effective they were at reducing mortality.
Jonathan Nguyen-Van-Tam, University of Nottingham (UK) and lead author of the study, explained: "There has been a lot of previous controversy about whether NAIs work in reducing serious complications and deaths due to influenza. Many countries stockpiled NAIs in readiness for a future pandemic. But it's fair to say that when the 2009 pandemic actually started we did not know if these 
drugs would reduce deaths - governments around the world had simply made a best estimate that this would probably be so."

The large meta-analysis, published recently in The Lancet Respiratory Medicine, tried to address this by assessing if NAI treatment affected mortality in patients hospitalized with confirmed or suspected H1N1 infection between January 2009 and March 2011. In total, 29,234 patients from 38 countries were included in the study. It was found that, irrespective of timing, NAI treatment reduced mortality risk when compared with no treatment (adjusted odds ratio [OR]: $0.81 ; 95 \% \mathrm{CI}: 0.70-0.93$; $\mathrm{p}=0.0024)$ and early treatment reduced mortality risk when compared with late treatment (adjusted OR: 0.48; 95\% CI: 0.41-0.56; p < 0.0001). However, it was observed that these findings were nonsignificant in children.

\section{“It was found that, irrespective of timing, neuraminidase inhibitor treatment reduced mortality risk

$$
\begin{gathered}
\text { when compared with no } \\
\text { treatment..." }
\end{gathered}
$$

"We did our best to assemble and combine all the data we could identify from around the entire globe and to perform the cleanest analysis possible, given the fact that it's unethical to do clinical trials during a pandemic," added Nguyen-VanTam. "From our results, it seems that in 2009, among patients hospitalized with the pandemic virus, the chances of dying could be reduced by roughly one half if an NAI was given with 48 hours of illness onset compared with no treatment. In my view, these data suggest that NAIs are a likely to be important in the fight against both seasonal and pandemic influenza."

Consequently, the authors conclude that NAI treatment should be used as soon as possible after the onset of flu symptoms in adults, particularly in hospitalized adults.

- Written by Natasha Leeson

Sources: Muthuri SG, Venkatesan S, Myles PR et al. Effectiveness of neuraminidase inhibitors in reducing mortality in patients admitted to hospital with influenza A H1N1pdm09 virus infection: a meta-analysis of individual participant data. Lancet Respir. Med. doi:10.1016/S2213-2600(14)70041-4 (2014) (Epub ahead of print); University of Nottingham press release: $w W W$. nottingham.ac.uk/news/pressreleases/2014/march/ tamiflu-saved-lives-during-swine-flu-pandemic,international-study-finds.aspx

\section{Light-activated antimicrobial surface is also effective in the dark, study suggests}

A new study, published recently in the journal Chemical Science, details how researchers from UCL (UK) have developed a new antibacterial material that may help reduce hospital infections.

Although hospitals try to reduce bacterial infections through strict cleaning policies, hospital-acquired infections are still a notable problem. Consequently, there is focus in research to find antibacterial coatings that will make surfaces less accommodating to bacteria.

One of the authors, Ivan Parkin, explained: "There are certain dyes that are known to be harmful to bacteria when subjected to bright light. The light excites electrons in them, promoting the dye molecules to an excited triplet state and ultimately produces highly reactive oxygen radicals that damage bacteria cell walls. Our project tested new combinations of these dyes along with gold nanoparticles, and simplified ways of treating surfaces which could make the technology easier and cheaper to roll out."

In this study, the researchers prepared bactericidal polymers by combining crystal violet, methylene blue and 2 -nm gold nanoparticles into medical grade silicone. They observed that even under intense light levels and when cleaned with an alcohol-based wipe, the coating remained stable. Furthermore, when compared with other photobactericidal polymers against both Staphylococcus epidermidis and Escherichia coli, it exhibited the strongest currently reported photobactericidal activity. The most interesting finding was that it also demonstrated significant antimicrobial activity under dark conditions.

"Despite contaminating the surface with far more bacteria than you would ever see in a hospital setting, placed under a normal fluorescent light bulb, the entire sample was dead in 3 to 6 hours, depending on the type of bacteria," explained lead author Sacha Noimark. "That was an excellent result, but the bigger surprise was the sample which we left in the dark. That sample too showed significant reductions in bacterial load, albeit over longer timescales of about 3 to 18 hours. The precise mechanism by which this dark-kill works is not yet clear, though."

- Written by Natasha Leeson

Sources: Noimark S, Allan E, Parkin IP. Light-activated antimicrobial surfaces with enhanced efficacy induced by a dark-activated mechanism. Chem. Sci. doi:10.1039/C3SC53186D (2014) (Epub ahead of print); UCL press release: www.ucl.ac.uk/news/newsarticles/0314/240314-antimicrobial-surface

\section{About the Bulletin Board}

The News highlights some of the most important events and research. If you have newsworthy information, please contact: Natasha Leeson, Commissioning Editor, Future Microbiology

Future Medicine Ltd, Unitec House, 2 Albert Place, London, N3 1QB, UK

n.leeson@futuremedicine.com 


\section{BULLETIN BOARD}

\section{Priority Paper Alerts}

Mike LA, Choby JE, Brinkman PR et al. Two-component system cross-regulation integrates Bacillus anthracis response to heme and cell envelope stress. PLoS Pathog. 10(3), e1004044 (2014).

Microbes face numerous challenges when trying to replicate within a vertebrate, such as large variations in temperature, oxygen and nutrient availability. Bacteria can adapt to such environments using two-component signaling systems (TCS). Here, the authors identified a new TCS (HitRS) in Bacillus anthracis and how it is activated by compounds that alter the integrity of the cell envelope. They also found that HitRS cross-signals with the heme-sensing TCS HssRS, so that the bacterium concurrently responds to to heme and cell envelope stress.

- Written by Natasha Leeson

Jorth P, Turner KH, Gumus P, Nizam N, Buduneli N, Whiteley M. Metatranscriptomics of the human oral microbiome during health and disease. MBio 5(2), pii: e01012-14 (2014).

The human microbiome is important for health, but when disrupted can cause disease. In this study, 160,000 genes were compared between healthy and diseased periodontal communities to show that individual species within the community do not have highly conserved metabolic gene expression profiles, whereas microbial communities do.

- Written by Natasha Leeson 